\title{
Novo Titular do Departamento de Direito do Trabalho
}

\section{A Redação}

\begin{abstract}
Em sessão solene da Congregação, realizada a 25 de agosto de 1982, no Salão Nobre, sob a presidência do Senhor Diretor, Professor Vicente Marotta Rangel, o novo titular do Departamento do Direito do Trabalho, Professor Octávio Bueno Magano, foi introduzido no recinto, com grande salva de palmas, pelos professores Antônio Chaves, Silvio Rodrigues e José Cretella Júnior para posse do cargo, nomeado por ato do Magnífico Reitor, publicado no Diário Oficial do Estado, de 13 de julho de 1982.

o Exmo. "Senhor Diretor, em seguida, convidou - Professor Silvio Rodrigues para proferir sua oração de recepção.
\end{abstract}

\section{Discurso do Professor Sílvio Rodrigues}

\section{Senhor Professor Octávio Bueno Magano.}

Hoje é dia de festa nesta Casa! $E$ dia de festa porque um de seus discípulos mais ilustres assume a cátedra de Direito do Trabalho, para a qual foi escolhido em memorável concurso. Neste momento recebe V. Exa., Senhor Professor, ao se empossar como titular desta Academia, a justa paga de seus esforços e o coroamento de uma formosa carreira dedicada ao estudo e ao ensino do Direito. Repito, hoje é dia de festa nesta Casa e ao acolhê-lo em nome de seus colegas de Congregação, é com a maior alegria que o saúdo e com igual júbilo que felicito a Faculdade de Direito de São Paulo, por esta nova e preciosa aquisição.

Imagino como deve estar feliz, meu nobre colega, e só lamento que não esteja assistindo a esta cerimônia, seu pai, o dr. Virgílio Magano, que em vida foi advogado dos mais conceituados do foro desta Comarca e que soube infundir nos filhos as qualidades que enalteciam seu caráter e seu amor às coisas do direito pois, de sua irmandade, além de V. Exa., dois outros saíram desta Casa. E quando se olha a projeção de V. Exa., na saudosa figura de seu pai, vê-se como é certa aquela assertação que por vezes se encontra na boca 
do povo, quando diz que a água cristalina corre, por onde a água cristalina já correu.

Não consigo fugir da emoção deste momento. Conheci Octávio Bueno Magano recém-saído da escola quando cortejava sua atual esposa, então minha parente por afinidade e que desde menina foi minha amiga muito querida. Fui padrinho de seu casamento e assim tive lugar de arquibancada para assistir o começo de carreira de nosso homenageado de hoje. Vi-o fazer concurso para Promotor de Justiça, para Juiz de Direito, para Presidente de Junta de Conciliação na Justiça do Trabalho. Vi-o deixar a magistratura para ingressar em um dos principais escritórios de advocacia de São Paulo, como sócio deste outro nosso ilustre colega que é o Prof. Cássio de Mesquita Barros.' Vi o sucesso profissional crescendo com seu esforço, crescendo com seu talento, crescendo com a crescente reputação dos ilustres titulares daquela banca advocatícia. Vi Octávio Bueno Magano chegar ao ápice da profissão !

$\mathrm{O}$ que entretanto se tornou surpreendente foi o fato de o profissional de tanto êxito não ter, com este apenas, ficado satisfeito.

De fato, desde seus primeiros anos de formado era fácil vislumbrar sua meta final, ou seja o assento nesta Congregação, e sempre a tendo em vista jamais se afastou da vida especulativa. À medida que exercia sua atividade paralela no magistério, primeiro na Universidade Mackenzie, depois nesta Casa, aprimorava seus conhecimentos não apenas na esfera de sua especialidade, mas por todo o campo do Direito.

Nestes anos de sua preparação e no curso de suas andanças, estava sempre a seu lado e delas participando, sua leal companheira e dedicada esposa, nossa querida Marlene. Vi-a sofrendo com suas angústias e sorrindo com suas vitórias. E hoje, que aparentemente o lidador chegou ao fim da luta, tem ela tanto direito de ser saudada no bastião da vitória, como o varão que honrou o nome de ambos.

A carreira de Octávio Bueno Magano é um exemplo que o dignifica e que honra a escola que o formou. Nesta fez seu curso de bacharelado, nela obteve os títulos de mestre, de doutor, de livre-docente, de professor adjunto e finalmente hoje, este, de professor titular, conquistado com grande brilho e galhardia. Em rigor, examinando-se sua vida pregressa de intelectual, verifica-se que todos os seus galardões foram conquistados na liça dos concursos, pois V. Exa. submeteu-se com sucesso a todas as provas universitárias.

Octávio Bueno Magano é um destemido e corajoso lutador, que abriu seu caminho com exclusivo esforço, sem precisar de favores nem de concessões. Aliás sua formação não se deu somente nas Arcadas, nem se restringiu ao campo específico do Direito do Trabalho, pois V. Exa. é Master of Comparative Law pela Columbia University no ano de 1961. E sei como lhe foram penosos, se bem 


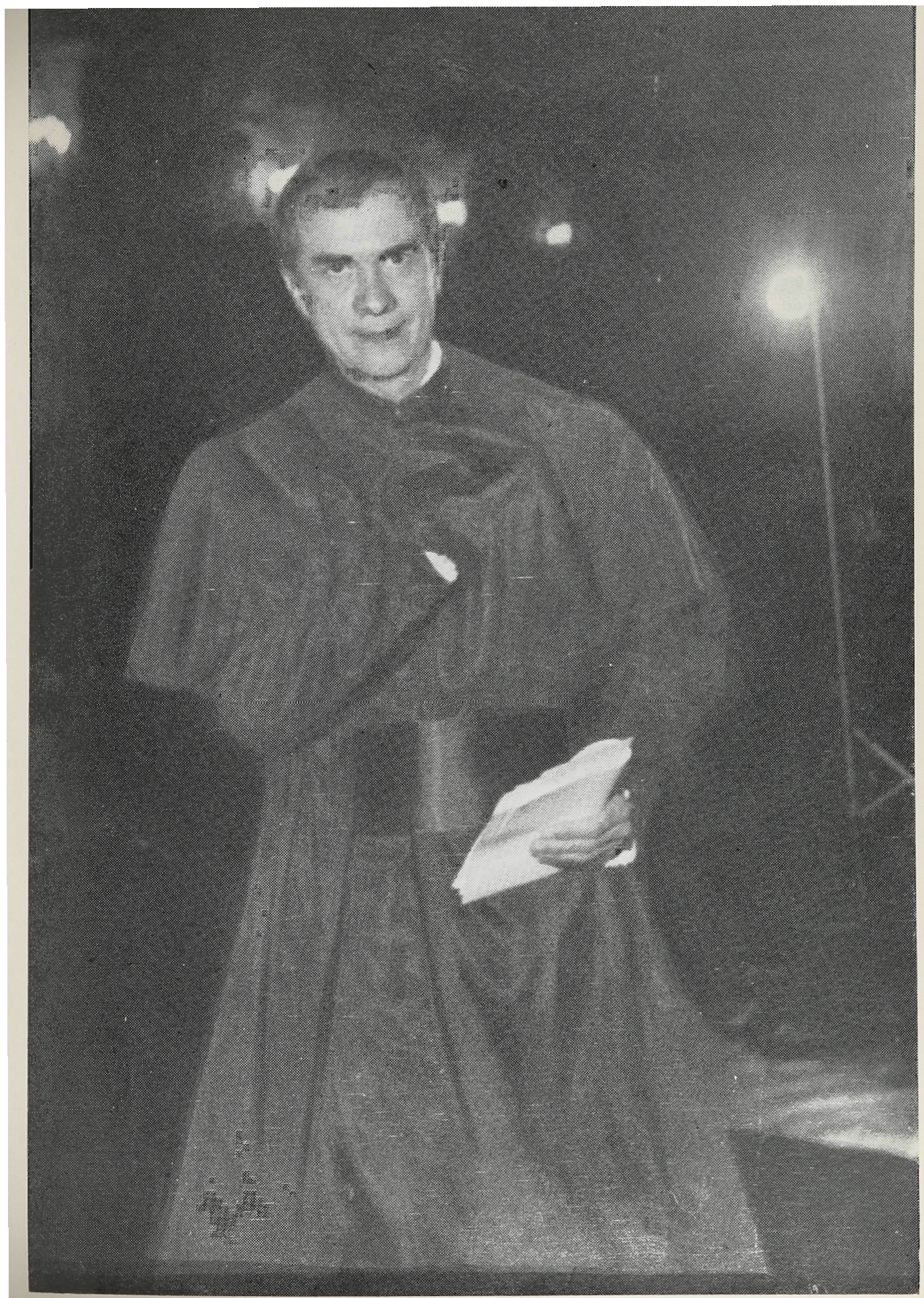

Professor Titular de Direito do Trabalho Dr. Octávio Bueno Magano 
que proveitosíssimos, os anos em que, nesta Casa, lecionou direito econômico.

Olhando o seu passado e examinando sua atividade intelectual, o analista se assombra ante a sua espantosa atividade e ante o enorme cabedal que ela oferece.

É V. Exa. um exemplo que nossos colegas de profissão, os advogados, se orgulharão de seguir, por seu espírito de luta, pela marcada probidade, pela lealdade e elegância com que sempre agiu e age.

Sua obra doutrinária, composta de livros e de uma centena de artigos publicados em revistas nacionais e estrangeiras, será sempre um repositório onde o estudioso encontrará a cada passo uma fonte inesgotável para seus estudos. Além das dezenas de trabalhos publicados em revistas brasileiras, há colaboradores em publicações da Venezuela, do Uruguai, da Argentina, na República Dominicana, do Paraguai, da Espanha, do México. De modo que o nome de V. Exa. transborda de nossas fronteiras, para ser conhecido e respeitado também no exterior.

Aliás a presença de V. Exa. no meio intelectual de outros países se revela através dos convites para Congressos Jurídicos, na maioria dos quais V. Exa. compareceu e defendeu temas que previamente enviou. Assim, no estrangeiro, defendeu teses sobre a "Solução dos Conflitos Coletivos do Trabalho", em Caracas; "El trabajo bajo y su Aspecto Jurídico" (em Lima), "O Seguro Social dos Acidentes de Trabalho (em Mendoza), "Legislação Trabalhista Brasileira Comparada com a Japonesa" e "Controle de Preços" (estes dois últimos no Japão), "A negociação coletiva no Setor Público" em San Juan de Porto Rico), "Grupos de Empresas Nacionais e Transacionais no Direito do Trabalho" (em Santo Domingo, República Dominicana), "El Procedimiento Ordinário", na Cidade do México.

Poderia continuar por muito tempo enumerando a participação brilhante de Octávio Bueno Magano em outros Congressos, no Peru, Paraguai, em Rosário, na Argentina, em Málaga, na Espanha, em Austin, nos Estados Unidos, etc. Como viram, omiti a participação de nosso homenageado em uma dezena de Congressos realizados no Brasil, onde sempre apareceu como figura atuante e incansável. Mas, pela breve relação que acabei de mencionar, é fácil verificar a pluralidade de temas de que se ocupou o Prof. Octávio Bueno Magano, no exterior firmando seu nome fora de nossa fronteira e elevando, assim, a reputação de nosso país. Sua importância é tão grande que V. Exa. já foi secretário e depois presidente do Instituto Latino Americano de Derecho del Trabajo e de la Seguridad Social, instituição da maior importância e que congrega a quase totalidade dos especialistas nesse campo do Direito. Assim é V. Exa. Sr. Prof. Octávio Bueno Magano, um dos juristas brasileiros mais conhecidos no exterior.

Já falei dos artigos de V. Exa., agora quero falar de seus livros. Antes de maiores detalhes creio necessário enumerar os principais: 
- Lineamentos do Direito do Trabalho, SP, 1969;

- Convenção Coletiva do Trabalho, SP, 1972;

- Dissídios Coletivos, em co-autoria com Cássio de Mesquita Barros, SP, 1965;

- Os grupos de empresas no Direito do Trabalho, SP, 1979;

- Manual de Direito do Trabalho - Parte Geral, SP, 1980;

- Manual de Direito do Trabalho - Direito Individual do Trabalho, SP, 1981;

- Lineamentos de Infortunística, SP, 1976;

- Organização Sindical Brasileira, SP, 1982.

Desses trabalhos cumpre distinguir os de caráter didático, daqueles que representam trabalho científico. Dentre os primeiros o mais antigo e intitulado "Lineamentos do Direito do Trabalho", editado, como disse, em 1969, traz um Prefácio de meu mestre Jorge Americano, tão moderado em seus elogios, mas que não os poupa ao se referir a Octávio Bueno Magano. Dentre as qualidades de nosso homenageado cumpre ressaltar a clareza, tão necessária ao Professor. A obra, aparentemente simples, é entretanto profunda e meditada. Não obstante, a preocupação didática se marca de maneira nítida no questionário, que se encontra ao fim de cada capítulo.

O professor que assinou aquele primeiro trabalho reaparece em seu Manual de Direito do Trabalho, já desta década. Apenas aqui já encontramos o homem maduro, encarando os problemas com grande profundidade e indiscutível argúcia, senhor absoluto do tema que preleciona. Se nada mais houvesse o nosso homenageado escrito, seu nome já ficaria gravado na galeria dos grandes mestres de sua especialidade.

A sua obra doutrinária entretanto é a de um grande jurista. Não me referirei senão àquelas de sua lavra exclusiva, deixando de lado os trabalhos feitos com outros escritores. Tal obra cobre todo o campo do Direito do Trabalho, desde a Organização Sindical Brasileira, aos Lineamentos de Infortunística, a Convenção Coletiva do Trabalho e outros. Tais trabalhos são profundos e esgotam a matéria. $\mathrm{O}$ mestre desce às raízes do Instituto. Se o seu leitor examinar qualquer deles vê que a pesquisa não é superficial; assim, e apenas a título de exemplo, menciono seu trabalho sobre a Infortunística; ali analisa o fundamento da proteção atribuída ao acidentado, o conceito e a extensão do conceito de acidente do trabalho, o seguro do acídente e sua natureza jurídica, sempre ansioso de saber e fixar as fontes que devem orientar o legislador e o juiz. Do mesmo padrão são seus outros trabalhos.

Entretanto, onde sua obra atinge o apogeu é nas duas monografias apresentadas a esta Congregação para concursos de cátedra, 
pois nelas os mestres de direito do trabalho e de direito econômico se fundem no mesmo homem e orientam a inspirada pena do escritor. São trabalhos memoráveis que têm lugar de relevo na literatura científica do direito brasileiro, e não seria em um discurso de saudação, por ocasião da posse de seu autor nesta Casa, que deveriam elas ser analisadas. Isso será certamente feito por críticos mais abalizados, embora seja impossível que estes tenham uma admiração mais profunda pelo escritor, do que o colega que ora o saúda.

Como disse, não pude sequer mencionar toda sua obra, Senhor Professor, porque é ela tão extensa que a mera enumeração ocuparia um enorme tempo, que não posso roubar dos seus amigos que, ora presentes, certamente estão ansiosos para abraçá-lo.

Este, de resto, é também meu anseio. Assim, ao encerrar esta oração quero dizer-lhe, mestre recém-chegado ao tope da carreira universitária, que o seu lugar estava de há muito reservado; quero repetir, que seus colegas de Congregação estão orgulhosos de sua presença, que esta Academia, ao consagrá-lo, está persuadida de que V. Exa. será, como já tem sido, um motivo de glória para ela. Assim, repito: "Hoje é dia de festa nesta Casa!" 